\title{
APUNTES SOBRE LA PROCEDENCIA DEL JUICIO DE GARANTÍAS CONTRA ACTOS DEL NOTARIO ACTUANDO COMO PARTICULAR EN FUNCIONES DE AUTORIDAD
}

\author{
Notes On The Appropriateness Of The Judgement Of Guarantees \\ Against Acts Of The Notary Acting As An Individual \\ In Authority
}

A la función notarial extraordinaria

Fabián HERNÁNDEZ HERNÁNDEZ*

Sumario:

I. Una teoría excepcional positiva II. El estado constitucional como sustento de la eficacia de los derechos fundamentales ante la función notarial III. Algo más sobre la función notarial IV. Evolución del concepto de autoridad para los efectos del amparo y la procedencia del juicio contra particulares $V$. Aplicación de la teoría excepcional positiva VI. Conclusión VII. Bibliografía

Resumen: En este artículo me propongo estudiar la función del notario público como manifestación del ejercicio de un poder que en ciertas condiciones puede crear, modificar o extinguir situaciones jurídicas concretas de trascendencia para los particulares, por lo cual, en esos casos, los actos derivados del ejercicio de la función notarial podrán ser objeto del juicio de amparo. En ese sentido, propongo una teoría excepcional positiva de la procedencia del amparo, siempre que se considere al notario como un particular en ejercicio de las funciones de la autoridad, lo cual supone reconocer una cierta concepción de los derechos humanos y del Estado constitucional.

Abstract: In this article I intend to study the role of the notary public as a manifestation of the exercise of a power that in certain conditions can create, modify or extinguish specific legal situations of importance for individuals, so that, in those cases, of the notarial function may be subject to the amparo suit. In that sense, I propose an exceptional positive theory of the provenance of amparo, provided that the notary is considered a private individual in the exercise of the functions of authority, which means recognizing a certain conception of human rights and the constitutional state.

Palabras clave: Notario, juicio de amparo, control constitucional, derechos fundamentales, autoridad, particular, eficacia horizontal de los derechos fundamentales, estado constitucional.

Keywords: Notary, amparo judgment, constitutional control, fundamental rights, authority, particular, horizontal effectiveness of fundamental rights, constitutional state.

\footnotetext{
*Licenciado en derecho por la Universidad de Guanajuato. Abogado. Colaborador y asesor en Notaría Pública 9, Celaya, Guanajuato.
} 


\section{Una teoría excepcional positiva}

El estado constitucional es la expresión más refinada del esfuerzo ancestral de la humanidad para ponerle bridas al ejercicio despótico del poder. En realidad, esta premisa sencilla me parece que condensa el espíritu del constitucionalismo y por tanto es el sustrato de la breve investigación que desarrollaré en lo sucesivo. La función de interdicción de la arbitrariedad explica y justifica la existencia de los mecanismos jurisdiccionales de control de la regularidad (como lo es el juicio de amparo), y también se encuentra detrás de la cada vez más expansiva eficacia de los derechos fundamentales, no sólo en las relaciones de los particulares frente al aparato estatal, sino incluso, cada vez con mayor incidencia, entre las relaciones de los particulares en forma coordinada, lo que antes era la esfera exclusiva y excluyente del derecho privado.

Pues bien, en este artículo propondré la defensa de una tesis positiva y expansiva que se inserta dentro del paradigma del estado constitucional, como telón de fondo de las recientes reformas constitucionales en materia de derechos fundamentales y amparo. La tesis que defiendo es que, para ciertos efectos, es decir, a partir de la intervención en cierta clase de actos jurídicos, la actividad del notario tiene efectos de trascendencia jurídica para los particulares, por lo cual entonces el juicio de amparo deberá proceder en contra de estos actos. Dicho en otras palabras: en ciertos casos, el notario debe ser considerado como autoridad para los efectos del amparo.

Empero, desde ahora, debo apresurarme a añadir un par de precisiones sobre las que volveré más adelante y que quedarán explicitadas en un momento posterior, pero que por de pronto es necesario ir adelantando. En principio cabe destacar que esta tesis se sostiene sólo para ciertos actos del notario en cuanto ellos tengan incidencia para ciertos efectos jurídicos de los particulares; por tanto, este no es un postulado general que pueda leerse como si se dijera que el notario siempre es autoridad para los efectos del juicio de garantías. Por el contrario, desde ahora debe aclararse que ello se sostiene sólo para ciertos actos, como se verá más adelante. De otra guisa, la segunda aclaración pertinente en este caso es que también considero que debe valorarse negativamente la postura jurisprudencial mayoritaria también en la doctrina que, con un carácter general, ha sostenido - como también se verá en un momento- que el notario nunca debe ser considerado como autoridad para el amparo. Esta tesis general negativa me parece que debe ser matizada, precisamente en los términos propuestos en el párrafo anterior.

Por tanto, en este opúsculo defenderé lo que denominaré una teoría excepcional positiva para la procedencia del amparo contra actos de autoridad provenientes del ejercicio de la función notarial, la cual se enclava normativamente como un ejemplo de procedencia del juicio de garantías contra particulares fundado en la fracción III del artículo $5^{\circ}$ de la Ley de Amparo, a partir de la reforma de 2013.

No obstante, para sostener esta postura considero que es necesario que antes me pronuncie brevemente sobre algunos postulados que me permitirán sustentar la argumentación que he desarrollado en esta parte y en los parágrafos que siguen. Las consideraciones que quiero proponer están relacionadas con el trasfondo del estado constitucional que permiten sostener el imperio de los derechos fundamentales en contra de particulares colocados en posiciones específicas, como lo es el ejercicio de la función notarial.

\section{El estado constitucional como sustento de la eficacia de los derechos fundamentales ante la función notarial}

Dije antes que el estado constitucional es la reacción contra toda forma de autoritarismo e incluso contra las más puras formas del positivismo que llegaran a su punto culminante en 
la primera mitad del siglo $\mathrm{XX}^{1}$. Este cambio de mentalidad se vio acompañado de una serie de técnicas jurídicas para asegurar que el derecho revista un cierto contenido axiológico que legitime su validez material. En realidad, el estado constitucional es un fenómeno complejo y multifactorial, por eso la nómina de las consecuencias que le son características puede elevarse ampliamente, pero para los efectos de esta investigación sólo consideraré los más esenciales y que son el punto de partida para el estudio del que ahora me ocupo.

En este sentido, lo primero que debe advertirse es que la constitución es norma jurídica plenamente vinculante; y que como norma es directamente aplicable por todos los operadores jurídicos, no sólo en las relaciones de supra a subordinación, es decir, de las autoridades con los gobernados, sino también en los vínculos de estos entre sí que, por regla general, suponen un plano de coordinación que era propio del derecho privado. La constitución ha dejado de ser un programa político o un conjunto de normas programáticas ${ }^{2}$ a ser desarrolladas por la intermediación legislativa, ahora es una norma plenamente obligatoria que sanciona su incumplimiento con la máxima conminación del sistema: la inconstitucionalidad ${ }^{3}$.

A ello debe agregarse que las normas constitucionales tienen una especial tipología. Frente a las concepciones positivistas más encumbradas que definían al derecho en los términos simplistas del conjunto de normas bilaterales, heterónomas y coercibles ${ }^{4}$, se opone la idea de que el derecho es más que un sistema de normas, ya que en el plano constitucional se dan encuentro otra clase de disposiciones de carácter abierto, es decir, los principios. Estos son mandatos de optimización ${ }^{5}$ que determinan la necesidad de realización de una conducta en la máxima medida de las condiciones fácticas y jurídicas posibles; a diferencia de las normas, que son imperativos definitivos que a una conducta unen una sanción —o se cumplen o no se cumplen-, los principios admiten un cumplimiento gradual, de manera que cuando algunas de estas normas entran en colisión será necesario ponderarlas a fin de determinar el peso específico del principio imperante ${ }^{6}$. Mientras que las normas, o se aplican o no se aplican y sus conflictos se deciden sólo mediante la declaración de invalidez o la determinación de una excepción a la regla general, los colisiones entre principios pueden decidirse en la dimensión del peso, procurando en lo general armonizar los dos principios en liza.

La constitución como norma y el ámbito de aplicación constitucional de los principios nos lleva a la consideración de un tercer efecto del estado constitucional, esto es, el paso de la validez formal - solamente - a la validez material del derecho. Probablemente la piedra de toque de esta tesis hayan sido los juicios a los ex líderes del nacionalsocialismo realizados en Núremberg al término de la Segunda Guerra Mundial7, así como los procesos judiciales seguidos a los centinelas del muro de Berlín, acusados de tirotear a quienes pretendían cruzar la frontera entre las dos Alemanias ${ }^{8}$. La ideología ${ }^{9}$ postulaba una separación conceptual entre el derecho y la moral, seguida de una neutralidad axiológica en la creación de las normas ${ }^{10}$, las cuales eran válidas

\footnotetext{
1 Atienza Rodríguez, Manuel (2006), Introducción al derecho, 2a reimp. México, Fontamara, p. 237.

2 Noriega Cantú, Alfonso (1987), Los derechos sociales creación de la revolución mexicana y la constitución de 1917, 2 a ed., México, IIJ/UNAM, p. 137.

3 Kelsen, Hans (2001), La garantía jurisdiccional de la constitución, México, IIJ/UNAM, pp. 56-85.

4 García Máynez, Eduardo (2006), Introducción al estudio del derecho, 49a edición, México, Porrúa, p. 36.

5 Alexy, Robert (2012), Teoría de los derechos fundamentales, $2^{\mathrm{a}}$ ed., Madrid, Centro de Estudios Políticos, p. 86.

6 Carbonell Sánchez, Miguel (2012), Argumentación jurídica, 2a ed. México, Porrúa-IIJ/UNAM, pp. IX-XXI.

7 Vigo, Rodolfo Luis (2008), La injusticia extrema no es derecho. De Radbruch a Alexy, México, Fontamara, pp. 131-173.

8 Ibid.

9 Boвbio, Norberto (2009), El problema del positivismo jurídico, 10 a reimp., México, Fontamara, p. 52.

${ }^{10}$ Kelsen, Hans (2005), Teoría pura del derecho, 14 a edición, México, Porrúa, p. 205.
} 
- en la teoría - en la medida en que resultaban de un proceso de creación establecido por la norma superior que sujetaba la formación del derecho sólo a requisitos procedimentales, con total prescindencia de sus contenidos materiales. Contra esto, el estado constitucional responde que no cualquier contenido puede ser derecho, por ello se postula que el derecho no puede ordenar cualquier cosa, que cuando la seguridad jurídica alcanzada por el derecho positivo no es nada en comparación de la iniquidad provocada, entonces el derecho debe ceder a la justicia ${ }^{11}$, porque la injusticia extrema no es derecho, y quien sostenga esta tesis puede reputarse como un no-positivista ${ }^{12}$.

Lo cierto es que por ahora no tenemos que penetrar a las profundidades de las disputas generadas por esta polémica en la filosofía del derecho. Para los efectos que pretendo ahora me basta con dejarlas apuntadas y proceder sólo a proyectar la luz que arrojan sobre un punto específico que se encuentra relacionado con la eficacia de los derechos fundamentes frente a particulares. Tal como lo sostiene Marco García Martínez en un provocador artículo publicado por la Universidad de Guanajuato - autor al cual sigo en esta parte- la teoría de la eficacia horizontal de los derechos fundamentales es la doctrina que sostiene la eficacia frente a terceros de los derechos fundamentales, desarrollada en Alemania a mediados del siglo $X X^{13}$. Se dice entonces que en este aspecto la doctrina discute qué tipo de eficacia despliegan los derechos fundamentales cuando se insertan en el seno de las relaciones desplegadas entre particulares: si lo hacen de manera mediata o inmediata ${ }^{14}$. En relación con esta disputa García Martínez apunta:

La teoría de la eficacia mediata o indirecta "condiciona la operatividad de los derechos fundamentales en el campo de las relaciones privadas a la mediación de un órgano del Estado, que sí está vinculado directamente a estos derechos." Lo anterior se logra a través de la intervención del legislador o del juzgador. Los partidarios de esta corriente discuten cuál de estos órganos estatales está llamado con carácter preferente a otorgar la tutela de los derechos fundamentales en el campo de las relaciones privadas, si el legislador o el juez. Por otro lado, la tesis de la eficacia inmediata afirma "la virtualidad directa, sin mediaciones concretizadoras, de los derechos fundamentales, en tanto derechos subjetivos reforzados por la garantía constitucional, frente a las violaciones procedentes de sujetos privados." Esta tesis, como señala Bilbao Ubillos, rompe con la doctrina liberal que solo concibe injerencias del Estado en la autonomía individual; no obstante, si advertimos que en la sociedad existen individuos o entidades no estatales con posiciones de poder frente a otros particulares, no parece adecuado discriminar entre violaciones del poder público y aquéllas cometidas por particulares.

En relación con el aspecto señalado en la larga cita de García Martínez, creo que lo más prudente, en consideración del actual desarrollo de la dogmática de los derechos humanos, es aceptar la teoría de la eficacia directa e inmediata de los derechos fundamentales en las relaciones entre particulares. Lo anterior, tomando en cuenta que la constitución, en tanto norma jurídica, no sólo puede disciplinar las relaciones de los órganos del estado, sino también (en una manifestación de constitucionalismo privado) los vínculos que eventualmente pueden establecerse entre particulares colocados en un mismo plano de jerarquía. Así por ejemplo, la ley

\footnotetext{
${ }^{11}$ RADbruCH, Gustav (2010), Introducción a la filosofía del derecho, 10 a reimp. México, Fondo de Cultura Económica, México, p. 134.

${ }^{12}$ Alexy, Robert (2008), "En defensa de la fórmula de Radbruch” en Vigo, Rodolfo Luis, La injusticia extrema no es derecho, op. cit. nota 5, p. 358.

${ }^{13}$ García Martínez, Marco (2016), "Mediación judicial: una aparente solución al problema procesal de la Drittwirkung der grundrechte", en Pérez Alonso, Eduardo y Olguín Torres, Antonio, Temas actuales de derecho constitucional, Guanajuato, Universidad de Guanajuato, pp. 85-107.

${ }^{14}$ Ibid.
}

CIENCIA JURÍdiCA. Departamento de Derecho. División de Derecho, Política y Gobierno, Universidad de Guanajuato - Año 7, No. 14, 2018 
fundamental puede incidir en las relaciones laborales, familiares o mercantiles que se establecen entre individuos aislados.

La cuestión de la eficacia directa de los derechos fundamentales, incluso en las relaciones de coordinación entre particulares, supone entonces que los sujetos no investidos formalmente de facultades de imperio, en el sentido tradicional de la palabra, también pueden en determinadas circunstancias afectar los derechos fundamentales. Como bien señala Francisco Mora Sifuentes en un reciente estudio, con la incorporación de los derechos al ordenamiento constitucional, tales normas adquieren

una fisonomía de derecho objetivo, derivada de su positivación en normas jurídicas indubitablemente eficaces, ubicadas en las gradas más altas del sistema. Se convertirán en criterios de ordenación para todo el sistema y, como decisiones básicas, merecedores de protección más allá de que exista o no pretensión individual. Lo anterior ha obligado a replantear varias tesis con las que la teoría del derecho venía trabajando ${ }^{15}$.

Me parece que la referencia de Francisco Mora Sifuentes proyecta luz sobre dos cuestiones que son ampliamente aplicables para el caso planteado en este estudio, pues asumir la función notarial como la manifestación de un cierto elemento que permite crear o modificar situaciones jurídicas de trascendencia para los particulares implica avanzar en el camino del reposicionamiento de las normas constitucionales en un sentido material y como auténticas normas jurídicas de carácter supremo; al tiempo que también requiere la ampliación de la esfera protectora de las garantías procesales de los derechos fundamentales. En cuanto a la primera cuestión, que tiene que ver con la dimensión axiológica y normativa de los derechos fundamentales, es preciso reconocer que Mora Sifuentes tiene razón al caracterizar con una precisa tipología las cualidades de las normas de derecho fundamental. Dice el profesor guanajuatense:

los derechos fundamentales pueden caracterizarse, entre otras cosas, por: a) su máximo rango, pues están contenidos en la norma constitucional, en el nivel superior del ordenamiento constitucional; b) su máxima fuerza jurídica al vincular como derecho directamente vigente al Legislativo, al Ejecutivo y al Judicial, y al estar su observancia plenamente controlada por los tribunales hasta culminar en el Tribunal Constitucional de Karlsruhe; c) su máxima importancia de objeto, al decidir las cuestiones básicas de la sociedad -la libertad contractual; garantía de la libertad de opinión, prensa, radio, televisión; libertad religiosa; protección a la vida y a la integridad física, etcétera-; y, finalmente, d) su máximo grado de indeterminación, que se advierte del carácter meramente sucinto lapidario y vacío del texto constitucional. La importancia de las normas constitucionales, como puede apreciarse, es tanto jerárquica como de con- tenido: no sólo es que estén al máximo nivel normativo, sino que también tienen por objeto las cuestiones básicas de la sociedad, acogiendo, por tanto, sus valores fundamentales. Se trata de la dimensión "material" o "axiológica" de la Constitución $y$ de la "fuerza integradora de los derechos fundamentales", ideas que, no debe olvidarse, tienen en la obra de Rudolf Smend un antecedente de primer orden.

En lo que respecta a la segunda cuestión relacionada con la expansión de las formas de garantía de los derechos, debemos advertir la permanente expansión de los mecanismos procesales de protección. En este caso es dable atestiguar el afianzamiento de la justicia constitucional como mecanismo de tutela secundaria de los derechos. Los mecanismos jurisdiccionales de protección constitucional deben ampliarse necesariamente en la misma proporción en que lo

\footnotetext{
${ }^{15}$ Mora Sifuentes, Francisco (2017), "La influencia de los derechos fundamentales en el ordenamiento: su dimensión objetiva”, en Boletín Mexicano de Derecho Comparado No. 150, septiembre-diciembre 2017, p. 1221.
} 
han hecho los contenidos protegidos por los derechos fundamentales. Así reconocemos nuevas formas de lesión de los bienes constitucionales valiosos para la vida de las personas. Ello incide desde luego en nuevo protagonismo de la judicatura sobre temas que antes estaban vedados a su intervención, como es el caso de las afectaciones ius-fundamentales, que pueden irrogarse a partir del ejercicio de la función notarial. Por ahora basta con dejar apuntada esta circunstancia sobre la que habré de volver más tarde cuando aborde el tema de la expansión del concepto de autoridad para los efectos del juicio de amparo. Por de pronto, basta con advertir la forma en cómo los actos del notario en funciones de este fedatario público pueden afectar los derechos de los particulares mediante el ejercicio de la fe pública; y si aceptamos este hecho y lo unimos a la tesis de la eficacia horizontal directa que acabo de exponer, entonces tendremos los primeros elementos para aceptar la procedencia del juicio de amparo contra ciertos actos del notario que afectan situaciones jurídicas de trascendencia para los particulares.

Para ello me concentraré ahora en dos aspectos que considero relevantes en este desarrollo. Primero proporcionaré una conceptualización de la doctrina dominante sobre la función notarial, y por otro lado, abordaré el desarrollo del concepto de autoridad para los efectos del juicio constitucional a fin de advertir desde qué momento y bajo qué condiciones este medio de control procede contra actos del notario.

\section{Algo más sobre la función notarial}

El fundamento constitucional de la función notarial se encuentra en el artículo 121 de la constitución, de acuerdo con el cual:

En cada Estado de la Federación se dará entera fe y crédito a los actos públicos, registros y procedimientos judiciales de todos los otros. El Congreso de la Unión, por medio de leyes generales, prescribirá la manera de probar dichos actos, registros y procedimientos, y el efecto de ellos, sujetándose a las bases siguientes: I. Las leyes de un Estado sólo tendrán efecto en su propio territorio, y, por consiguiente, no podrán ser obligatorias fuera de él. II. Los bienes muebles e inmuebles se regirán por la ley del lugar de su ubicación. III. Las sentencias pronunciadas por los tribunales de un Estado sobre derechos reales o bienes inmuebles ubicados en otro Estado, sólo tendrán fuerza ejecutoria en éste, cuando así lo dispongan sus propias leyes. Las sentencias sobre derechos personales sólo serán ejecutadas en otro Estado, cuando la persona condenada se haya sometido expresamente o por razón de domicilio, a la justicia que las pronunció, y siempre que haya sido citada personalmente para ocurrir al juicio. IV. Los actos del estado civil ajustados a las leyes de un Estado, tendrán validez en los otros. $V$. Los títulos profesionales expedidos por las autoridades de un Estado, con sujeción a sus leyes, serán respetados en los otros.

De acuerdo con la exégesis del notario Eduardo García Villegas ${ }^{16}$, el artículo mencionado contiene en realidad varias previsiones que debemos atender. La primera parte del texto dispone que en cada Estado de la Federación se dará entera fe y crédito a los actos públicos, registros y procedimientos judiciales de todos los otros, asimismo, el texto constitucional prevé que el Congreso de la Unión, por medio de leyes generales, prescriba la manera de probar dichos

\footnotetext{
${ }^{16}$ En el desarrollo de estas ideas seguiré de cerca las posturas de GArcía Villegas, Eduardo (2006), "La función notarial", comunicación en el Colegio de Notarios, Septiembre de 2006.
} 
actos, registros y procedimientos, y el efecto de ellos, sujetándose a cinco bases específicas. Un aspecto que debe destacarse es la consagración constitucional de la fe pública.

La fe, en su sentido etimológico aceptado por la Real Academia Española, es sinónimo de certeza o seguridad, es decir, significa creer en algo que no nos consta, que no hemos percibido por alguno de los sentidos. Según el origen de la autoridad, la fe, o es religiosa o es humana. La fe religiosa es la que proviene de la autoridad divina que ha revelado algo a los seres humanos; la humana proviene de afirmaciones hechas por el hombre. Si la fe humana proviene de una autoridad privada, es decir, común, se llama fe privada. A esa clase pertenecen los documentos privados, es decir, firmados por particulares, y que no tienen nada de fe pública si no son reconocidos legalmente ante alguna autoridad ${ }^{17}$.

Si el documento, por el contrario, proviene de o es emitido por una autoridad pública o por una persona investida de fe pública, estamos en presencia de un documento público y, por lo tanto, en un caso de documento que tiene aparejada la fe pública. Son muy diversas las fuentes que llaman fe pública a la calidad de documentos determinados suscritos por funcionarios cuyas aseveraciones, cumplidas determinadas formalidades, tienen la virtud de garantizar la autenticidad de los hechos narrados y, por consiguiente, su validez y eficacia jurídica. En función de la fe pública se imprime la autenticidad de lo narrado, que es la verdad de lo acontecido sin que ello importe sentar juicio subjetivo de la verdad, la cual pertenece de modo absoluto a la conciencia de los actores. Si el contenido de los documentos de fe pública fuera la verdad esencial, estaríamos en presencia de la infalibilidad. No existe texto legal alguno, ni sistema jurídico alguno que confiera semejante virtud a los documentos así construidos. La fe pública, desde la antigüedad, apareja seguridad y certeza de los derechos que supone su recíproco respeto, sin lo cual no existiría la paz social. Dicha fe pública siempre debe constar en forma documental. La tiene y crea el Estado con el fin de brindar seguridad jurídica. La fe pública es, por una parte, obligatoria, esto es, no depende de la voluntad de los individuos en particular; la sociedad tiene el deber de creer en ella; y por otra parte, nace del Estado por su derecho a auto-determinarse de manera soberana. Es así como el estado determina la forma de otorgar seguridad jurídica al conglomerado pasivo universal, que es uno de sus fines primordiales ${ }^{18}$.

Por todo lo anterior, García Villegas concluye lo siguiente:

La fe pública del notario significa la capacidad para que aquello que certifica sea creíble. Esta función del notario contribuye al orden público, a la tranquilidad de la sociedad en que actúa, y da certeza que es una finalidad del derecho. Si bien la fe pública es la garantía que da el Estado, la fe notarial es la garantía que da el notario al Estado y al particular al determinar que el acto se otorgó conforme a derecho y que lo relacionado en él es cierto, proporcionando así la seguridad jurídica ${ }^{19}$.

Ahora bien, aunque la notaría comparte la fe que le delega el poder ejecutivo para dar crédito de ciertos actos que pasan por su fe, lo cierto es que el común de la doctrina es conteste, al señalar que la función notarial no es "parapública", esto, para reafirmar que tiene un matiz complejo muy especial: resulta claro que los notarios no son servidores públicos. Por lo cual, se invocan criterios como los siguientes:

\footnotetext{
${ }^{17}$ Ibíd. p. 12.

18 Ídem.

19 Ídem.
} 
NOTARIOS. NO SON SERVIDORES PÚBLICOS. Conforme al artículo 108 de la Constitución Política de los Estados Unidos Mexicanos se reputan como servidores públicos, entre otros, los representantes de elección popular y quienes desempeñen un empleo, cargo o comisión en la administración pública. Ahora bien, toda vez que el notario actúa por medio de una patente otorgada por el Estado, no puede ser considerado servidor público, en atención a que su cargo no es de elección popular ni se halla dentro de la administración pública estatal o municipal, además de que el notario no depende del gobierno o de una entidad paraestatal, ya que si bien actúa por delegación del Estado, no está dentro de su organización administrativa ni burocrática.

Así, al analizar la función notarial y la esencia de los actos del notario, parece decirse por parte de la Suprema Corte que la fe pública es originalmente un atributo del Estado que tiene por virtud de su imperio y es ejercitada a través de los órganos estatales y del notario. De acuerdo con el sistema jurídico mexicano, el notario, sin formar parte de la organización del Poder Ejecutivo, es vigilado por él y por disposición de la ley recibe la fe pública del Estado por medio de la patente respectiva. La fe pública notarial debe considerarse como la garantía de seguridad jurídica que da el notario tanto al Estado como al particular, al determinar que el acto se otorgó conforme a derecho y que lo relacionado con él es cierto ${ }^{20}$.

La tesis sostenida en la ejecutoria citada podría considerarse como el locus común de la doctrina sobre la materia. Pero lo que es más, aún después de la reforma en materia de derechos fundamentales de 2011 y las modificaciones a la Ley de Amparo posteriores, existen autores notables que no dudan en mantener la idea de que el notario, para ningún efecto, puede ser considerado en una posición de prevalencia para afectar derechos de las personas. Tal es el parecer de Bernardo Pérez Fernández del Castillo, cuyas opiniones al respecto pasaré a comentar ahora. Pérez Fernández del Castillo es autor de uno de los tratados de derecho notarial más citados y conocidos en el medio, así, en la última edición de su Derecho notarial editado en marzo de 2017, cuando el autor aborda el tema de la naturaleza jurídica de la función notarial, textualmente afirma:

La actividad notarial no encaja dentro de [las] organizaciones administrativas. No hay la relación jerárquica existente en la centralización, pues al Jefe de Gobierno y a las autoridades competentes les corresponde aplicar la ley y vigilar su cumplimiento, no así los de revisión y nulificación de los actos del inferior, resolución de conflictos y nombramientos, toda vez que la expedición de la patente de notario está sujeta a requisitos legales consistentes en la aprobación del examen de aspirante y el triunfo en el de oposición ${ }^{21}$.

Por tanto, Pérez Fernández del Castillo concluye que la naturaleza de la relación jurídica que existe entre el notario y el particular puede ser, o bien la derivada de un contrato de prestación de servicios profesionales, o bien ser una relación mixta y compleja, compuesta por un reglamento de carácter arancelario, por la prestación de un servicio profesional y el desempeño de un servicio público de carácter obligatorio ${ }^{22}$. Sin embargo, el autor no dice más al respecto, lo que es sorprendente si tomamos en cuenta que estas afirmaciones se hacen en la edición de 2017 cuando ya estaban plenamente asentadas las modificaciones en materia de juicio de amparo. Entonces podríamos pensar que deberían contarse con más elementos para bordar alrededor de la tesis que sostengo en este estudio, pues el propio Pérez Fernández del Castillo cuenta con

\footnotetext{
${ }^{20}$ Ídem.

${ }^{21}$ Pérez Fernández del Castillo, Bernardo (2017), Derecho notarial, $20^{a}$ edición, México, Porrúa, p. 176.

${ }^{22}$ Ibídem. p. 179.
} 
elementos que no desarrollaría en su texto, pero que apuntarían en la misma dirección que quiero sostener en esta contribución.

Otro ejemplo de la postura dominante de la que me separo es precisamente la sostenida por Pascual Orozco Garibay, quien en vista de la reforma constitucional de 2011 se pregunta si el notario puede ser autoridad para los efectos del amparo. En las conclusiones de su estudio, afirma:

1.- El notario es un particular profesional del Derecho, investido de fe pública por el Estado que brinda seguridad jurídica y certeza en los actos y hechos de los que da fe, de una manera imparcial. El notario no es una autoridad y por ello no se le puede imponer la obligación consignada en el artículo $1^{\circ}$ constitucional a las autoridades de promover, respetar, proteger $y$ garantizar los derechos humanos, ni tampoco forma parte del poder judicial, que es el órgano facultado y obligado en los términos de los criterios jurisprudenciales antes citados, para realizar un control constitucional y convencional y, en su caso, inaplicar una norma jurídica por considerar que no está conforme con la Constitución o con los Tratados Internacionales en materia de Derechos Humanos. 2.- La obligación del notario es aplicar la ley, sea ésta federal o local que regula el acto jurídico que se va a otorgar o formalizar, sin calificar su constitucionalidad o convencionalidad. 3.- El notario no es autoridad responsable para los efectos del juicio de amparo, ya que no cumple con los requisitos para que se le puede equiparar como autoridad, ya que en los actos jurídicos en que interviene siempre es a petición de parte y con el consentimiento de los comparecientes, no es unilateral, obligatoria ni coactiva ${ }^{23}$.

Me parece que Garibay está en un error que trataré de demostrar en la parte final de este estudio. Al margen de lo anterior, creo que ya tenemos los elementos para perfilar los confines de la tesis dominante en este campo, donde se decía que el notario no tenía calidad de autoridad para los efectos del amparo ni aún después de la reforma al régimen procesal del juicio de garantías, pues el artículo 50., fracción II de la Ley de Amparo, establece la norma que regula las notas características del acto de autoridad, en cuanto crean, modifican o extinguen situaciones jurídicas en forma unilateral y obligatoria, así como identifica como autoridad a los particulares, cuyas funciones estén determinadas por una norma general que los faculte para realizar actos equivalentes a aquellos que afecten derechos en términos de esta fracción.

En ese sentido, la intervención de un notario en la elaboración de una escritura, no le otorga la calidad de autoridad responsable en el juicio de amparo, porque no dicta, ordena, ni ejecuta un acto que crea, modifica o extingue situaciones jurídicas en forma unilateral y obligatoria, sino que únicamente da fe y protocoliza el acto de la autoridad judicial. Esto es, la objetiva posibilidad legalmente prevista de que un ente del gobierno o un particular puedan ser considerados como autoridades responsables para efectos del juicio de amparo, deriva de la naturaleza y características propias del acto que emiten u omiten, pues no sólo debe tener las cualidades específicas señaladas de unilateralidad y obligatoriedad, sino que también deben trascender o impactar en la esfera jurídica del gobernado, creando, modificando o extinguiendo situaciones jurídicas o fácticas, siempre que esa posibilidad para el particular derive de una facultad expresa conferida por normas generales.

En esas condiciones, si bien es cierto que aunque el artículo 50., fracción II, de la Ley de Amparo establece que, para los efectos de la propia ley, los particulares tendrán la calidad de autoridad responsable cuando realicen actos equivalentes a los de autoridad que afecten derechos en los términos de la citada fracción y cuyas funciones estén determinadas por una norma general;

\footnotetext{
${ }^{23}$ Orozco Garibay, Pascual (2016), “¿El notario es una autoridad responsable?”, en Escribano. Revista de todos los notarios, No. 74, p. 32.
} 
también lo es que el notario público no se encuentra en ese supuesto, pues lo que se reclama de éste es cualquier acto tendente a tirar la escritura del inmueble materia del juicio de origen, lo que implica que únicamente dará fe del acto de adjudicación, con lo cual, da la forma de escritura pública a ese acto para efecto de su inscripción. Pero el notario no actúa por sí y ante sí, de manera unilateral, para afectar la esfera jurídica de la quejosa, máxime que los notarios públicos son sólo auxiliares de la administración de justicia y están obligados a prestar sus servicios profesionales cuando para ello fueren requeridos por las autoridades, por los particulares o en cumplimiento de resoluciones judiciales.

No obstante, como se verá en el siguiente apartado, lo cierto es que una concepción más amplia del tema dará lugar a que se conteste negativamente a propuestas como las anteriores, pues tal como se dijo con antelación, para ciertos casos y efectos, el notario desde luego deberá tener el carácter de autoridad responsable.

Para ello primero me ocuparé de la segunda cuestión que dejé apuntada y en el siguiente numeral expondré la forma en que el concepto de autoridad, para los efectos del amparo, fue variando a lo largo del tiempo hasta llegar a aceptarse la procedencia del juicio contra actos de ciertos particulares colocados en situaciones especiales, como es la función notarial.

\section{Evolución del concepto de autoridad para los efectos del amparo y la procedencia del juicio contra particulares}

Uno de los aspectos por el que debemos preguntarnos - con mayor prontitud e importancia- en este breve opúsculo en torno a la naturaleza autoritativa del notario público, para los efectos del egregio juicio constitucional de amparo, es una cuestión de carácter general, la cual está representada por la naturaleza genérica de la autoridad para los efectos del juicio de derechos fundamentales.

Sin entrar en grandes complicaciones, pues en este aspecto nos encontramos frente a una cuestión de teoría general del amparo que puede aceptarse sin grandes complicaciones, es dable decir que, para el amparo, es autoridad y, por ende, puede ser sujeto pasivo de la relación procesal de carácter constitucional, como todo órgano estatal investido de facultades de decisión o ejecución, con cuyo ejercicio crea, modifica o extingue situaciones generales o concretas, de hecho o jurídicas, con trascendencia particular y determinada de una manera imperativa ${ }^{24}$. De esta manera, son autoridades los órganos a quienes la ley instituye con atribuciones para expedir órdenes o prevenciones que afecten particularmente o en su conjunto a los particulares, así como los entes que están encargados de hacer cumplir esas determinaciones, ya sea por sí mismos o por medio de una autoridad determinada. Las autoridades de la primera especie se denominan ordenadoras en tanto que las del segundo grupo reciben el nombre de ejecutoras, según la conocida práctica forense observable en prácticamente todas las demandas de amparo. La dicotomía entre ordenadoras y ejecutoras indica que cuando se solicita el amparo contra un acto de un ente ordenador éste debe ser pasado o presente; pero cuando se trata de una ejecución, también puede ser futuro inminente ${ }^{25}$.

La definición del concepto de autoridad ha presentado una evolución importante desde el asentamiento de este medio de control y, también es menester decirlo, desde el momento en que puede rastrearse el primer pronunciamiento judicial en la materia, derivado del caso de Mar-

\footnotetext{
${ }^{24}$ Burgoa Orihuela, Ignacio (2003), Derecho constitucional mexicano, $17^{\text {a }}$ edición, México, Porrúa, p. 874.

${ }^{25}$ Ibídem. p. 875 . 
colfo Torres en $1918^{26}$. En 1918 Torres promovió una demanda de amparo en donde señaló como autoridad a Canuto Ortega, quien siendo mayor del ejército exigió al quejoso que lo acompañara con la intensión de privarlo de la libertad. El juez de distrito negó el amparo porque el mayor del ejército no era una autoridad sino un particular, con lo cual, el amparo resultaba improcedente. En revisión ante la Suprema Corte, se revocó la sentencia y se concedió el amparo. Este primer criterio de la Corte fue en el siguiente sentido:

El termino autoridades para los efectos del amparo, comprende a todas aquellas personas que disponen de la fuerza pública, en virtud de circunstancias, ya legales, ya de hecho, y que, por lo mismo, estén en posibilidad material de obrar como individuos que ejerzan actos públicos, por el hecho de ser pública la fuerza de que disponen ${ }^{27}$.

A decir de Genaro Góngora Pimentel y José Alfredo Muñoz Delgado (a quien sigo en todo este apartado), la integración de esta tesis presentó problemas desde su inicio porque uno de los precedentes se refería a la negativa de los directores de una escuela para inscribir a un alumno en donde no se hacía ninguna referencia al concepto de fuerza pública ${ }^{28}$.

Por eso, el criterio que nació del caso Marcolfo dejó fuera los actos de muchas autoridades que de hecho lo eran, pero no recurrían a la fuerza pública. Esta situación cambió cuando la Corte amplió la noción de la autoridad para los efectos del juicio constitucional, pues consideró como autoridad responsable al Instituto Mexicano del Seguro Social en la ejecutoria del 6 de marzo de 1947, toda vez que era característica de este organismo tener una función de imperio que le permite ordenar y ser obedecido por los particulares. Ello ocasionó que a partir de entonces los organismos de esta clase fueran considerados como "partes demandadas" en el juicio constitucional, de acuerdo a que la ley que los crea y les concede facultades para expedir y ejecutar actos que tienen las características de los que emite cualquier otra autoridad ${ }^{29}$.

Sin embargo, el criterio hasta antes de la nueva Ley de Amparo llegó en 1997 cuando, a decir de Muñoz Delgado, se planteó la necesidad de abandonar el criterio de la fuerza pública, aceptado desde 1918 para sustituirlo por otro que no dejara en estado de indefensión a los gobernados, así se señalaba que: no puede fijarse una regla general más bien debe analizarse en cada caso si se trata de un acto en el que el poder público puede o no, con fundamento en una norma jurídica, afectar de manera unilateral los derechos de los particulares, creando, extinguiendo o modificando situaciones jurídicas concretas.

El criterio de referencia fue aprobado por el Tribunal Pleno del Máximo Órgano Jurisdiccional el 10 de febrero de 1997, para establecer que:

[...] autoridades para efectos del amparo, comprende a todas aquellas personas que disponen de la fuerza pública, cuyo primer precedente data de 1919 [...] la aplicación generalizada de éste en la actualidad conduce a la indefensión de los gobernados, pues estos organismos en su actuación, con independencia de la disposición directa que lleguen a tener o no de la fuerza pública, con fundamento en una norma legal pueden emitir actos unilaterales a través de los cuales crean, modifican o extinguen por sí o ante sí, situaciones jurídicas que afectan la esfera legal de los gobernados, sin la necesidad de acudir ante los órganos judiciales ni del consenso de la voluntad del afectado. Esto es, ejercen facultades decisorias que les están atribuidas en

\footnotetext{
${ }^{26}$ Góngora, Genaro (2003), Introducción al estudio del juicio de amparo, $9^{a}$ edición, México, Porrúa, pp. 2-20.

27 Quinta época, Cuarta Sala, Apéndice de 1995, parte HO, tesis 1103, p. 763

${ }^{28}$ Góngora, Genaro, op. cit. nota 26, p. 18.

${ }^{29}$ Comentario personal que me fue dirigido por el profesor José Alfredo Muñoz Delgado, el 16.02.2016, cuando impartí la charla sobre la función notarial en el nuevo milenio, en la ciudad de Aguascalientes.
} 
la ley y que por ende constituyen una potestad administrativa, cuyo ejercicio es irrenunciable y que por tanto se traducen en verdaderos actos de autoridad al ser de naturaleza pública la fuente de tal potestad... por ello el juzgador de amparo, a fin establecer si a quien se atribuye el acto de autoridad para efectos del juicio de amparo, debe atender a la norma legal y examinar si lo faculta o no para tomar decisiones o resoluciones que afectan unilateralmente la esfera jurídica del interesado, y que deben exigirse mediante el uso de la fuerza pública o bien a través de otras autoridades ${ }^{30}$.

Sin embargo, lo cierto es que una de las más importantes innovaciones que presenta la Ley de Amparo consiste en la previsión de que el amparo procede para la salvaguarda del quejoso en contra de los actos de la autoridad, o bien, provenientes de los particulares en los casos en los que lo determine la propia regulación secundaria, como lo determina el artículo $1^{\circ}$ de la Ley de Amparo en su último párrafo. Las modernas formas de organización de la actividad administrativa del estado, como las actuales formas de manifestación de las fuerzas del mercado, han demostrado con suficiente claridad que los entes de autoridad no son los únicos que pueden conculcar con sus actos u omisiones los derechos fundamentales de las personas, sino que, por el contrario, también los poderes privados deben ser sometidos a un selecto escrutinio de su actividad. Ello ha hecho palpable la necesidad de que los derechos fundamentales también sean exigibles en las relaciones horizontales o de coordinación entre los particulares; este fenómeno particularmente estudiado por la jurisprudencia del Tribunal Constitucional Alemán, es un modelo apto para la plena realización del ideal máximo del estado constitucional. Por otro lado, que la eficacia de los derechos fundamentales también en las relaciones inter privatos exigen de la confección de nuevos mecanismos procesales o la adaptación de los existentes para lograr la eficacia de los derechos. En esta tendencia debemos inscribir los cambios suscitados al régimen procesal del amparo, en lo que hace a este tema.

Esta es la descripción del fenómeno que subyace al tema esencial tratado en este inciso, sin embargo, aún debemos despejar la duda de si después de la reforma el amparo es procedente en contra de particulares. Para ello debemos partir de los términos precisos de la regulación de la materia. En este sentido, debe entenderse el último párrafo del artículo $1^{\circ}$ de la Ley de Amparo y la fracción II del numeral $5^{\circ}$ del mismo ordenamiento - en el último párrafo- determina que: Para los efectos de esta Ley, los particulares tendrán la calidad de autoridad responsable cuando realicen actos equivalentes a los de autoridad, que afecten derechos en los términos de esta fracción, y cuyas funciones estén determinadas por una norma general.

La previsión que se hace en el anterior numeral de la ley reglamentaria del juicio constitucional implica la previsión expresa de la procedencia de la acción de amparo para proteger a los gobernados también contra ciertos actos u omisiones de los particulares que vulneren los derechos fundamentales reconocidos en la normativa suprema. Esto, como una clara aplicación de la eficacia horizontal de los derechos fundamentales. Pese a esta circunstancia lo más correcto es pensar que la Ley de Amparo no es tan extensiva en lo que hace a los sujetos que pueden figurar como autoridades responsables, es decir, aquellos que pueden ser llamados al juicio como pasivos de la relación procesal. Lo anterior es de este modo ${ }^{31}$ porque cuando el artículo comentado hace referencia a los particulares, siempre se implica el presupuesto de que estos cumplan ciertas funciones de autoridad con base en una ley previamente establecida. Así, el ordenamiento procesal del amparo prevé la procedencia del amparo contra particulares que

\footnotetext{
${ }^{30}$ La tesis citada presenta los siguientes datos de localización: Novena época, Pleno, Semanario Judicial de la Federación y su Gaceta, tomo V, febrero de 1997, tesis P.XXVII/97, p. 118.

${ }^{31}$ Ferrer, Eduardo y Sánchez, Rubén (2015), El nuevo juicio de amparo, México, Porrúa, p. 165. 
materialmente se colocan en la posición de autoridades de hecho y de derecho. La afirmación de la procedencia del amparo contra actos de particulares se debe matizar en el sentido de aceptarla únicamente en cuanto tales actos se coloquen en una posición propiamente de autoridades, con base en una regla de derecho positivo, y no en todos los casos como una lectura a primera vista y poco meditada podría conducir a pensar.

El tema de la ampliación del concepto de autoridad para los efectos del juicio de amparo se relaciona de forma directa con la cuestión relativa a la expansión de las formas de garantía de los derechos fundamentales, cuestión a la que me referí en el apartado II y que dejé en ese momento pendiente para abordarla ahora. En estas condiciones el juicio de amparo, a pesar de la reforma constitucional de 2011 y la nueva ley de amparo de 2013, parece que exclusivamente procede exclusivamente contra actos de los poderes públicos, implicando que los actos de particulares continúen siendo ajenos al control de los jueces constitucionales. Así, aunque el juicio de amparo en el orden jurídico sea improcedente contra actos de particulares, no se sigue que los derechos de las personas no sean vulnerados en las relaciones entre los particulares ni tampoco que en esas relaciones los derechos se garantizan a través de los procesos ordinarios, cuyas sentencias son impugnables a través del amparo directo o indirecto pero referidos sólo a la autoridad que resolvió. En este aspecto la transformación del amparo no significó mayor eficacia. Esto no se puede compartir, por las razones que refiero a lo largo de este estudio.

\section{Aplicación de la teoría excepcional positiva}

Sostengo entonces que para ciertos casos el notario debe ser considerado como autoridad para los efectos del juicio de amparo. Esta afirmación, como dije más arriba, obedece a la intervención del notario sólo para ciertos hechos y no de manera general. Es decir, que cuando el notario interviene para certificar documentos o para dar una fe de hechos es difícil que se pueda decir que con ello modifica situaciones jurídicas de trascendencia, o cuando calcula impuestos, que debe retener en una compraventa, pues en estos casos lo cierto es que la fuente del acto de autoridad se encuentra en una ley diversa.

Así, no puede concederse al acto del notario carácter de acto de autoridad al cálculo o la retención de impuestos que en notario realiza en una compraventa, pues la actuación del notario carece de obligatoriedad, ya que no tiene la posibilidad legal de vencer directamente cualquier clase de resistencia de los contribuyentes para cumplir en forma voluntaria las obligaciones fiscales a su cargo, lo cual propicia que el sentido de afectación del acto en la esfera jurídica del gobernado sea prácticamente inexistente.

En ese sentido se juzga acertado el pronunciamiento visible en la tesis PC.XVIII. J/12 K (10a.), proveniente de Plenos de Circuito, visible en la Gaceta del Semanario Judicial de la Federación, Libro 32, Julio de 2016, Tomo II, página: 1429, en donde se determinó lo siguiente:

NOTARIO PÚBLICO. NO ES AUTORIDAD PARA EFECTOS DEL JUICIO DE AMPARO CUANDO CALCULA, RETIENE Y ENTERA LOS DERECHOS POR INSCRIPCIÓN EN EL REGISTRO PÚBLICO DE LA PROPIEDAD Y LOS IMPUESTOS SOBRE ADQUISICIÓN DE BIENES INMUEBLES Y ADICIONALES, CON MOTIVO DE LA FORMALIZACIÓN DE UNA ESCRITURA PÚBLICA (LEGISLACIÓN DEL ESTADO DE MORELOS). En términos de los artículos 77 de la Ley General de Hacienda, del 94 Bis al 94 Bis-12 -vigentes hasta el 6 de noviembre de 2013- y del 119 al 125 de la Ley General de Hacienda Municipal, 27, 28, 49, 50 y 182 del Código Fiscal, 12 y 57 del Reglamento de la Ley del Registro Público de la Propiedad y del Comercio, así como 1o., 20., 31, fracción VII, 
y 73 de la Ley del Notariado, todos del Estado de Morelos, el notario público es el particular que actúa como fedatario de los actos y hechos que los interesados le someten para su protocolización, constituyéndose en auxiliar de la administración pública local en la recaudación tributaria, cuando con motivo de la formalización de una escritura pública respectiva calcula, retiene y entera los derechos por inscripción en el Registro Público de la Propiedad y los impuestos sobre adquisición de bienes inmuebles y adicionales. En tales circunstancias, el notario no tiene el carácter de autoridad responsable ni realiza actos equivalentes a los de autoridad para efectos del juicio de amparo, conforme al artículo 5o., fracción II, de la Ley de Amparo, porque su relación con los contribuyentes no es de supra a subordinación, pues a pesar de que sus funciones están determinadas por normas generales y actúa de manera unilateral, no crea, modifica o extingue, por sí y ante sí, situaciones jurídicas que afectan la esfera jurídica de aquéllos, al precisar de la voluntad de estos para llevar a cabo su intervención; además, la actuación del notario carece de obligatoriedad, ya que no tiene la posibilidad legal de vencer directamente cualquier clase de resistencia de los contribuyentes para cumplir en forma voluntaria las obligaciones fiscales a su cargo, lo cual propicia que el sentido de afectación del acto en la esfera jurídica del gobernado sea prácticamente inexistente. De ahí que, al no tratarse de un acto de autoridad y al no estar obligado quien lo emite a fundarlo y motivarlo, el contribuyente no puede promover juicio de amparo contra la actuación del notario en la que se aplicaron las leyes que se tildan de inconstitucionales; sin embargo, si en la escritura pública correspondiente aparecen citados los fundamentos legales de los conceptos de la retención, a partir de ese momento surge la oportunidad para impugnar las leyes aplicadas y comienza a correr el plazo a que se refiere la jurisprudencia 2a./J. 47/2013 (10a.), de la Segunda Sala de la Suprema Corte de Justicia de la Nación, de título y subtítulo: "DERECHOS POR INSCRIPCIÓN EN EL REGISTRO PÚBLICO DE LA PROPIEDAD EN EL ESTADO DE MORELOS. EL PLAZO PARA PROMOVER EL JUICIO DE AMPARO CONTRA EL ARTÍCULO 77 DE LA LEY GENERAL DE HACIENDA DE LA ENTIDAD, DEBE COMPUTARSE A PARTIR DE QUE EL NOTARIO PÚBLICO HAGA LA RETENCIÓN CORRESPONDIENTE, SIEMPRE QUE SE ACREDITE QUE EL QUEJOSO TUVO PLENO CONOCIMIENTO DE SU APLICACIÓN".

Por el contrario, en otros supuestos, por ejemplo en los casos de tramitación de un juicio sucesorio testamentario ante notario, es claro que su actuación podrá ser controvertible en amparo, pues es claro que el notario dicta, ordena y ejecuta actos que crean modifican y extinguen situaciones jurídicas de forma unilateral y obligatoria, pues se sustituye a una autoridad jurisdiccional. Y si bien son las partes quienes acuden motu proprio ante el fedatario para solicitar sus servicios, lo mismo ocurre con el Juez civil o familiar. Por ello, si el notario advierte que no se cumplen con los requisitos legales puede negarse a tramitar el referido procedimiento, pero si acepta conocerlo, a través de su intervención creará, modificará o extinguirá situaciones jurídicas concretas. De ahí lo unilateral de su actuación que, además, se materializa con la autorización que con su sello y firma valida los instrumentos que pasan ante su fe. Así se reconoce en la tesis II.20.C.5 K (10a.) de los Tribunales Colegiados de Circuito, visible en la Gaceta del Semanario Judicial de la Federación, Libro 25, Diciembre de 2015, Tomo II, página: 1291, donde se dispone:

NOTARIO PÚBLICO. CUANDO TRAMITA UN PROCEDIMIENTO SUCESORIO TESTAMENTARIO, ES AUTORIDAD RESPONSABLE, PARA EFECTOS DEL JUICIO DE AMPARO. El artículo 5o., fracción II, segundo párrafo, de la Ley de Amparo vigente, 
otorga a los particulares la calidad de autoridades responsables, siempre y cuando cumplan con diversos requisitos: a) que realicen actos equivalentes a los de autoridad, es decir, que dicten, ordenen, ejecuten o traten de ejecutar un acto que crea, modifica o extingue situaciones jurídicas en forma unilateral y obligatoria; $u$ omitan el acto que de realizarse crearía, modificaría o extinguiría dichas situaciones jurídicas; b) que a través de esos actos u omisiones afecten derechos; $y, c)$ que sus funciones estén determinadas por una norma general. Ahora bien, el notario es un particular, profesional del derecho a quien el Estado ha otorgado nombramiento para ejercer las funciones propias del notariado, investido de fe pública; así, cuando un notario público tramita un procedimiento sucesorio testamentario realiza actos equivalentes a los de autoridad, en este caso, de una autoridad jurisdiccional, pues actúa en auxilio del Poder Judicial y aplica preceptos normativos tanto del Código Civil como del de Procedimientos Civiles. En efecto, el notario al tramitar este tipo de procedimiento testamentario, a petición de parte, como ocurre con la autoridad jurisdiccional, inicia y radica la sucesión testamentaria, siempre y cuando conste el acta de defunción del autor de la herencia, califica que el testamento se haya otorgado con las formalidades de ley, solicita informe al Archivo General de Notarías y al Registro Público de la Propiedad respecto de la existencia de algún otro testamento, confiere el cargo de albacea, efectúa el reconocimiento de derechos hereditarios, inventario y partición hasta otorgar escritura pública de adjudicación. En ese sentido, es claro que el notario dicta, ordena y ejecuta actos que crean modifican y extinguen situaciones jurídicas de forma unilateral y obligatoria, pues se sustituye a una autoridad jurisdiccional, y si bien son las partes quienes acuden motu proprio ante el fedatario para solicitar sus servicios, lo mismo ocurre con el Juez civil o familiar. Por ello, si el notario advierte que no se cumplen con los requisitos legales, puede negarse a tramitar el referido procedimiento, pero si acepta conocerlo, a través de su intervención creará, modificará o extinguirá situaciones jurídicas concretas; de ahí lo unilateral de su actuación que, además, se materializa con la autorización que con su sello y firma valida los instrumentos que pasan ante su fe. Asociado a ello, al efectuar el reconocimiento de derechos hereditarios, inventario y partición del patrimonio del de cujus, estos actos quedarán firmes y serán obligatorios tanto para las partes como para terceros, lo que afectaría derechos tanto de posibles herederos como el de terceros. Finalmente, las funciones del notario están determinadas por una norma general, la Ley del Notariado, que lo faculta para conocer del procedimiento sucesorio testamentario, además de los Códigos Civil y de Procedimientos Civiles.

Existe además un caso genérico que origina la procedencia del juicio de amparo contra actos del notario, cuando de su actuar se dé fe respecto de actos violatorios de derechos humanos, como se dice en el criterio VI.10.A.34 K (10a.), donde se señala:

\section{NOTARIOS PÚBLICOS QUE REALIZAN ACTOS EQUIVALENTES A LOS DE AUTORI- DAD. REVISTEN TAL CARÁCTER, PARA EFECTOS DEL JUICIO DE AMPARO, CUANDO DAN FE DE ACTOS O HECHOS VIOLATORIOS DE DERECHOS HUMANOS (LEGISLA- CIÓN DEL ESTADO DE PUEBLA). De conformidad con el último párrafo de la fracción II del artículo 5o. de la Ley de Amparo, los particulares tendrán la calidad de autoridad responsable cuando realicen actos equivalentes a los de autoridad, que afecten derechos en los términos de dicha fracción y cuyas funciones estén determinadas por una norma general. En el caso de los notarios del Estado de Puebla, sus funciones están determinadas por la Ley del Notariado de la referida entidad federativa, en vigor a partir del primero de enero de dos mil trece, en cuyo artí- culo 47, fracción $V$, se establece que están impedidos, entre otras cuestiones, para dar fe de actos o hechos que sean violatorios de derechos humanos. Por tanto, si la aludida Ley del Notariado}


se expidió con posterioridad a la reforma del artículo 1o. constitucional, de diez de junio de dos mil once, y en cumplimiento a lo en éste ordenado, se establece en aquélla el impedimento para los notarios de dar fe de actos o hechos que sean violatorios de derechos humanos, cuando en la demanda de amparo se plantea precisamente que el notario responsable con su actuar viola derechos humanos de la parte quejosa, es inconcuso que a dicho fedatario síle reviste el carácter de autoridad responsable para los efectos del juicio de amparo.

\section{Conclusión}

Como hemos visto, parece que la actitud más prudente no es la de formular un criterio que niegue de manera llana la procedencia del juicio contra actos del notario, como tampoco es correcto afirmar que siempre procederá el juicio contra los citados fedatarios. Sino que en todo caso deberá analizarse cada caso concreto para ver si se surten las siguientes condiciones: a) que los notarios, en el caso concreto, realicen actos equivalentes a los de autoridad, es decir, que dicten, ordenen, ejecuten o traten de ejecutar un acto que crea, modifica o extingue situaciones jurídicas en forma unilateral y obligatoria; u omitan el acto que de realizarse crearía, modificaría o extinguiría dichas situaciones jurídicas; b) que a través de esos actos u omisiones afecten derechos; y, c) que sus funciones estén determinadas por una norma general. Si se surten todas estas hipótesis, entonces procederá el amparo contra actos del notario colocado en una situación de particular.

\section{Bibliografía}

Alexy, Robert (2012), Teoría de los derechos fundamentales, $2^{\mathrm{a}}$ ed., Madrid, Centro de Estudios Políticos.

Atienza Rodríguez, Manuel (2006), Introducción al derecho, 2ª reimp. México, Fontamara.

Bоввіо, Norberto (2009), El problema del positivismo jurídico, 10 a reimp., México, Fontamara.

Burgoa Orihuela, Ignacio (2003), Derecho constitucional mexicano, $17^{\text {a }}$ edición, México, Porrúa.

Carbonell Sánchez, Miguel (2012), Argumentación jurídica, 2a ed. México, Porrúa-IIJ/ UNAM.

Ferrer, Eduardo y Sánchez, Rubén (2015), El nuevo juicio de amparo, México, Porrúa.

García Martínez, Marco (2016), "Mediación judicial: una aparente solución al problema procesal de la Drittwirkung der grundrechte", en PÉrez Alonso, Eduardo y Olguín Torres, Antonio, Temas actuales de derecho constitucional, Guanajuato, Universidad de Guanajuato, pp. 85-107

García Máynez, Eduardo (2006), Introducción al estudio del derecho, 49ª edición, México, Porrúa.

García Villegas, Eduardo (2006), "La función notarial”, comunicación en el Colegio de Notarios, Septiembre de 2006. 
Góngora, Genaro (2003), Introducción al estudio del juicio de amparo, 9a edición, México, Porrúa.

Kelsen, Hans (2001), La garantía jurisdiccional de la constitución, México, IIJ/UNAM.

Kelsen, Hans (2005), Teoría pura del derecho, 14 edición, México, Porrúa.

Orozco Garibay, Pascual (2016), “¿El notario es una autoridad responsable?”, en Escribano. Revista de todos los notarios No. 74, segundo trimestre de 2016, pp. 25- 32.

Mora Sifuentes, Francisco (2017), "La influencia de los derechos fundamentales en el ordenamiento: su dimensión objetiva”, en Boletín Mexicano de Derecho Comparado No. 150, septiembre-diciembre 2017, pp. 1215-1258.

Noriega Cantú, Alfonso (1987), Los derechos sociales creación de la revolución mexicana y la constitución de 1917, 2ª ed., México, IIJ/UNAM.

Pérez Fernández Del Castillo, Bernardo (2017), Derecho notarial, 20 a edición, México, Porrúa.

RAdbruch, Gustav (2010), Introducción a la filosofía del derecho, 10ª reimp., México, Fondo de Cultura Económica, México.

Vigo, Rodolfo Luis (2008), La injusticia extrema no es derecho. De Radbruch a Alexy, México, Fontamara. 
